\title{
Pertumbuhan Kebutuhan Sekolah Menggunakan Graph
}

\author{
Andriani Arisa Safitri', Alvi Dwi Ningrum², Muhammad Rizky Utama ${ }^{3}$, M.Ainul Yaqin ${ }^{4}$ \\ 1,2,3,4Teknik Informatika, Fakultas Sains dan Teknologi, Universitas Islam Negeri Maulana Malik \\ Ibrahim Malang \\ Jl. Gajayana No.50, Dinoyo, Kec. Lowokwaru, Kota Malang, Jawa Timur 65144 \\ *116650039@student.uin-malang.ac.id,216650054@student.uin-malang.ac.id, \\ 316650038@student.uin-malang.ac.id,4yaqinov@ti.uin-malang.ac.id
}

\begin{abstract}
Quality schools are schools that are able to implement 8 Standards of National Education Standards set by the Government. These standards are made so that schools are capable of conducting good and qualified teaching and learning activities in all fields of education. Until the school can achieve maximum results from the standards given. In achieving that there are things that need to be done beforehand, namely school needs analysis. From the analysis it can be seen the growth of school needs. Growth in school needs is needed as a key to achieving quality schools. This research uses graphs to illustrate every growth that occurs in a school with the criteria for increasing students. The method used for data processing uses AHP (Analytic Hierarchy Process).
\end{abstract}

Keywords: AHP (Analytic Hierarchy Process), Growth, Requirement, School

\section{Abstrak}

Sekolah yang berkualitas adalah sekolah yang mampu menerapkan 8 Standar dari Standar Nasional Pendidikan yang ditetapkan oleh Pemerintah. Standar tersebut dibuat agar sekolah mampu dalam melakukan aktivitas belajar mengajar yang baik dan mumpuni di segala bidang pendidikan. Hingga sekolah dapat mencapai hasil maksimal dari standar yang diberikan. Dalam mencapai hal itu terdapat hal-hal yang perlu dilakukan sebelumnya, yaitu analisis kebutuhan sekolah. Dari analisis dapat diketahui pertumbuhan kebutuhan sekolah. Pertumbuhan kebutuhan sekolah sangat diperlukan sebagai kunci untuk mencapai sekolah yang berkualitas. Dipenelitian ini menggunakan graph untuk menggambarkan setiap pertumbuhan yang terjadi disekolah dengan kriteria pertambahan siswa. Metode yang digunakan untuk proses pengolahan data menggunakan AHP (Analytic Hierarchi Process).

Kata kunci: AHP (Analytic Hierarchy Process), Kebutuhan, Pertumbuhan, Sekolah

\section{PENDAHULUAN}

Setiap organisasi pendidikan sangat membutuhkan analisis pertumbuhan kebutuhan sekolah untuk meningkatkan kualitas sekolah supaya bisa memenuhi Standar Nasional Pendidikan (SNP). Standar Nasional Pendidikan (SNP) adalah kriteria minimal tentang sistem pendidikan di seluruh wilayah hukum Negara Kesatuan Republik Indonesia. Standar nasional pendidikan terdiri atas standar isi, proses, kompetensi lulusan, tenaga kependidikan, sarana dan prasarana, pengelolaan, pembiayaan, dan penilaian pendidikan yang harus ditingkatkan secara berencana dan berkala yang diatur dalam Peraturan Pemerintah Nomor 19 tahun 2005 [1]. Dalam pertumbuhan kebutuhan tersebut, terdapat 8 Standar yang ditetapkan didalam SNP. Tentu saja, sekolah harus mempunyai kualitas yang baik, karena sekolah sebagai sarana belajar bagi siswa-siswi bangsa. 
Kualitas yang baik berguna untuk meningkatkan mutu pembelajaran yang dapat diberikan sekolah kepada siswa-siswinya, sehingga mereka lebih mendapatkan ilmu yang baik pula. Untuk mendapatkan sekolah berkualitas yang sesuai dengan SNP, tidak serta merta terjadi begitu saja. Banyak hal yang harus dilakukan oleh sekolah sebelumnya. Seperti, peninjauan kurikulum, pembangunan fasilitas sekolah dan lain lain. Dengan begitu, diharapkan dengan peninjauan yang terus dilakukan, sekolah bisa mencapai hasil maksimal. Kebutuhan-kebutuhan sebelumnya itulah yang menciptakan adanya pertumbuhan sekolah. Untuk mendapatkan pertumbuhan kebutuhan sekolah diperlukan analisis mulai dari kebutuhan minimal dari berlangsungnya sekolah hingga kebutuhan maksimal yang harus dicapai sekolah. Pertumbuhan kebutuhan sekolah ini akan digunakan untuk mengetahui proses pertumbuhan dari sekolah dan mendapatkan nilai pertumbuhan. Dalam hal ini diperlukan perhitungan pertumbuhan sekolah yang menggunakan metode Analytical Hierarchy Process (AHP) untuk menentukan faktor-faktor yang mempengaruhi pertumbuhan sekolah.

AHP (Analytic Hierarchy Process) adalah suatu teori umum tentang pengukuran yang digunakan untuk menemukan skala rasio, baik dari perbandingan berpasangan yang diskrit maupun kontinyu. AHP menguraikan masalah multi faktor atau multi kriteria yang kompleks menjadi suatu hirarki. Hirarki didefinisikan sebagai suatu representasi dari sebuah permasalahan yang kompleks dalam suatu struktur multi level dimana level pertama adalah tujuan, yang diikuti level faktor, kriteria, sub kriteria, dan seterusnya ke bawah hingga level terakhir dari alternatif. Dengan hirarki, suatu masalah yang kompleks dapat diuraikan ke dalam kelompok-kelompoknya yang kemudian diatur menjadi suatu bentuk hirarki sehingga permasalahan akan tampak lebih terstruktur dan sistematis [2]. Jurnal ini bertujuan menggambarkan arsitektur visi dan arsitektur bisnis Universitas Sebelas Maret sebagai bagian dari tahapan perencanaan arsitektur enterprise Universitas Sebelas Maret dengan menggunakan framework TOGAF. Hasil yang diperoleh berupa principal catalog untuk arsitektut enterprise UNS, arsitektur visi Universitas Sebelas Maret yang terdiri dari Value Chain Diagram, Stakeholder Map Matrix, Solution Concept Diagram dan arsitektur bisnis Universitas Sebelas Maret yang terdiri dari business process diagram dan functional decomposition diagram [3].

Penelitian untuk rancangan sistem informasi yang akan digunakan sebagai pendukung pemenuhan standar nasional pendidikan di Sekolah dan Sekolah memiliki Blue Print atau Model Arsitektur Enterprise yang dapat digunakan untuk merancang dan mengembangkan sistem informasi [4]. Pemodelan teknologi informasi dapat dilakukan dengan memanfaatkan Enterprise Architecture menggunakan Enterprise Architecture Framework, yaitu dengan menggunakan Treasury Enterprise Architecture Framework. Pemodelan teknologi informasi ini ditinjau dari designer perspective yang menghasilkan work products yang berfokus pada desain proses, model informasi, komponen dan desain aplikasi pada Sekolah Tinggi Kesehatan.Hasil penelitian ini berupa dokumen pemodelan EA yang dapat dijadikan acuan untuk dapat menentukan future state dan strategi yang dilakukan pada Sekolah Tinggi Kesehatan [5]. 


\section{METODOLOGI PENELITIAN}

Arsitektur bisnis direpresentasikan dalam bentuk struktur organisasi, deskripsi kerja, prosedur operasi baku, dan model proses bisnis. Dalam struktur organisasi terdapat deskripsi kerja dalam setiap bagian di dalamnya. Setiap deskripsi kerja mempunyai kebutuhan dalam pelaksanaannya. Kebutuhankebutuhan tersebut juga dapat dijadikan metrik pengukuran skala dan kompleksitas organisasi. Kebutuhan-kebutuhan tersebut meliputi bahan atau material, personil, peralatan, metode atau prosedur kerja, dan uang. Kebutuhankebutuhan tersebut merepresentasikan perencanaan produksi, sehingga pada setiap deskripsi kerja tersebut ada target kerjanya. Prosedur operasi baku merupakan salah satu komponen dalam perhitungan skala deskripsi kerja. Setiap deskripsi kerja memiliki prosedur operasi baku untuk melaksanakannya. Prosedur operasi baku direpresentasikan dalam bentuk model proses bisnis. Model proses bisnis dinotasikan dengan BPMN. Dengan demikian skala dan kompleksitas untuk arsitektur bisnis dapat diukur melalui metrik- metrik yang didapatkan dari struktur organisasi dan model proses bisnis.

Struktur organisasi seringkali direpresentasikan dalam bentuk tree. Metrikmetrik yang digunakan untuk mengukur skala dan kompleksitas struktur organisasi didapatkan melalui tree tersebut. Metrik- metrik tersebut adalah jumlah node, jumlah edge, kedalaman rata-rata (average depth), dan weight. Dengan metode AHP didapatkan formula skala dan kompleksitas struktur organisasi

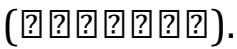

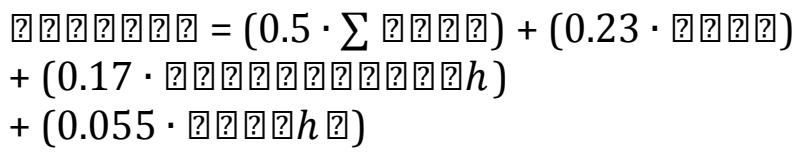

Representasi tree formula ini adalah :

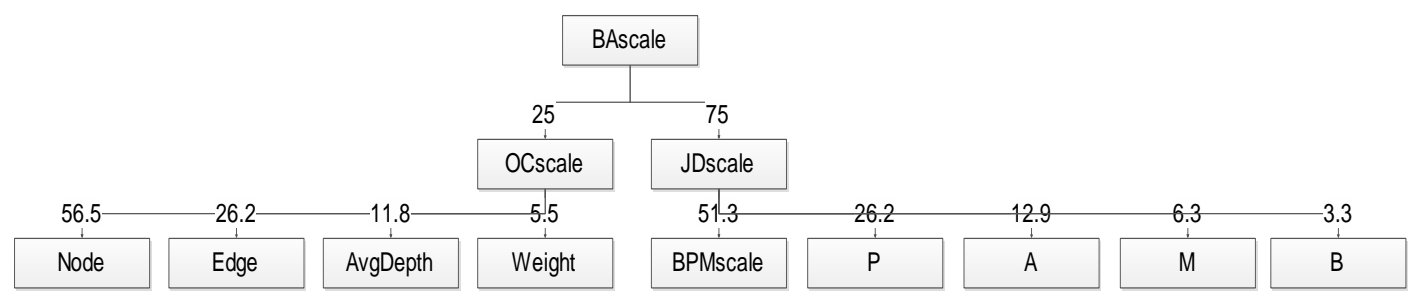

Gambar 1. Tabel Graph

\section{HASIL DAN PEMBAHASAN}

\subsection{Pertumbuhan 1}

Pada pertumbuhan 1, ditentukan minimal requirement yang ada dalam sekolah. Minimal requirement sebagai kebutuhan yang paling awal yang dibutuhkan untuk berjalannya sebuah sekolah. Di dalamnya ditentukan sebanyak 32 siswa. Akomodasi berupa lab. komputer, lab. IPA, kamar mandi, dan kelas masing2 diberikan 1 ruangan. Pengajar masih hanya guru dan diberikan 2 guru saja. 


\subsection{Pertumbuhan 2}

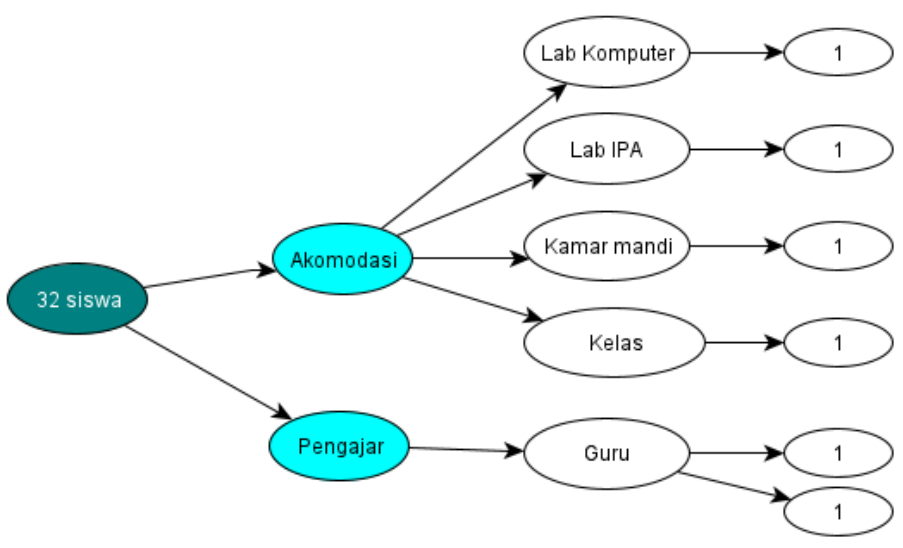

Pada pertumbuhan 2, terlihat pertumbuhan yang terjadi pada sekolah dengan peningkatan jumlah siswa dari pertumbuhan 1 yang sebesar 32 siswa menjadi 64 siswa. Akomodasi juga bertambah ruang kamar mandi dan kelas sebanyak 2 buah. Begitu juga dengan guru yang bertambah sebanyak 4 orang. Terdapat pula penambahan fasilitas lain pada sekolah dalam sektor kesehatan dan keamanan. Dalam sektor kesehatan terdapat UKS dan petugas medis. Dalam sektor keamanan ditambahkan satpam untuk menjaga kemanan sekolah.

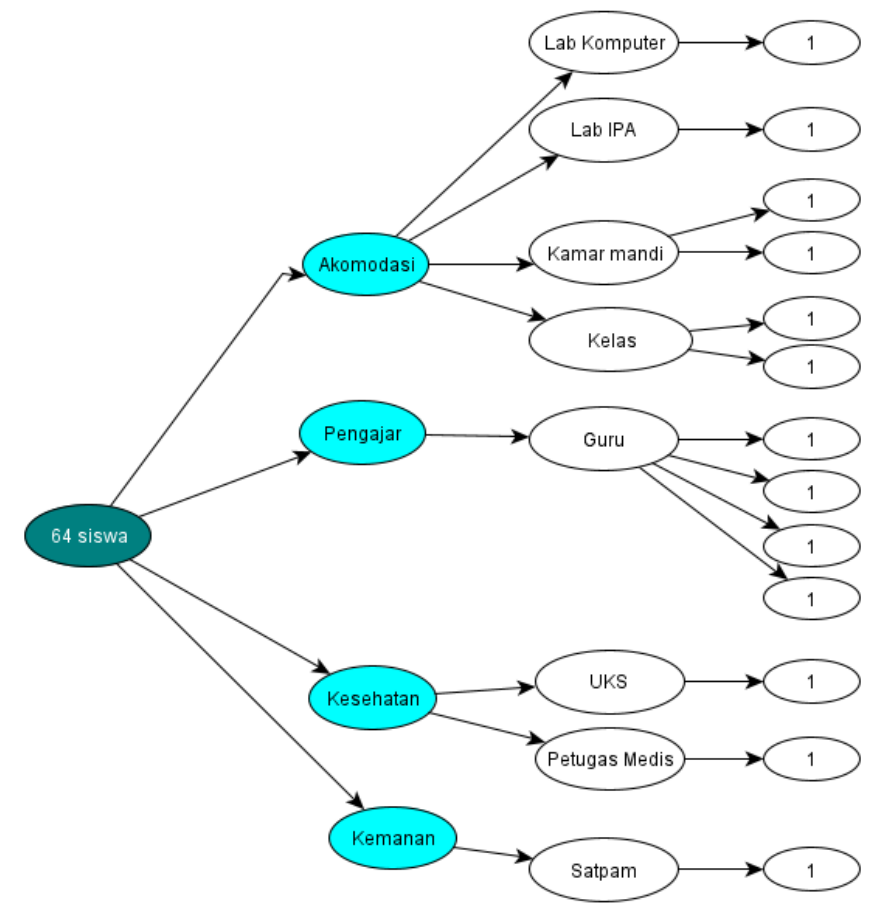

Gambar 3. Pertumbuhan 2 


\subsection{Pertumbuhan 3}

Pada pertumbuhan 3, jumlah siswa naik menjadi 96 siswa. Begitu juga di bagian akomodasi, kelas dan kamar mandi bertambah menjadi 3 ruangan. Jumlah guru bertambah sebanyak 6 orang. Dalam fasilitas kesehatan ditambahkan ambulance untuk membantu siswa yang sakit secara darurat dan pertugas medis pun bertambah juga menjadi 3 orang. Untuk menambah keamanan di sekolah satpam juga ditambahkan menjadi 3 orang.

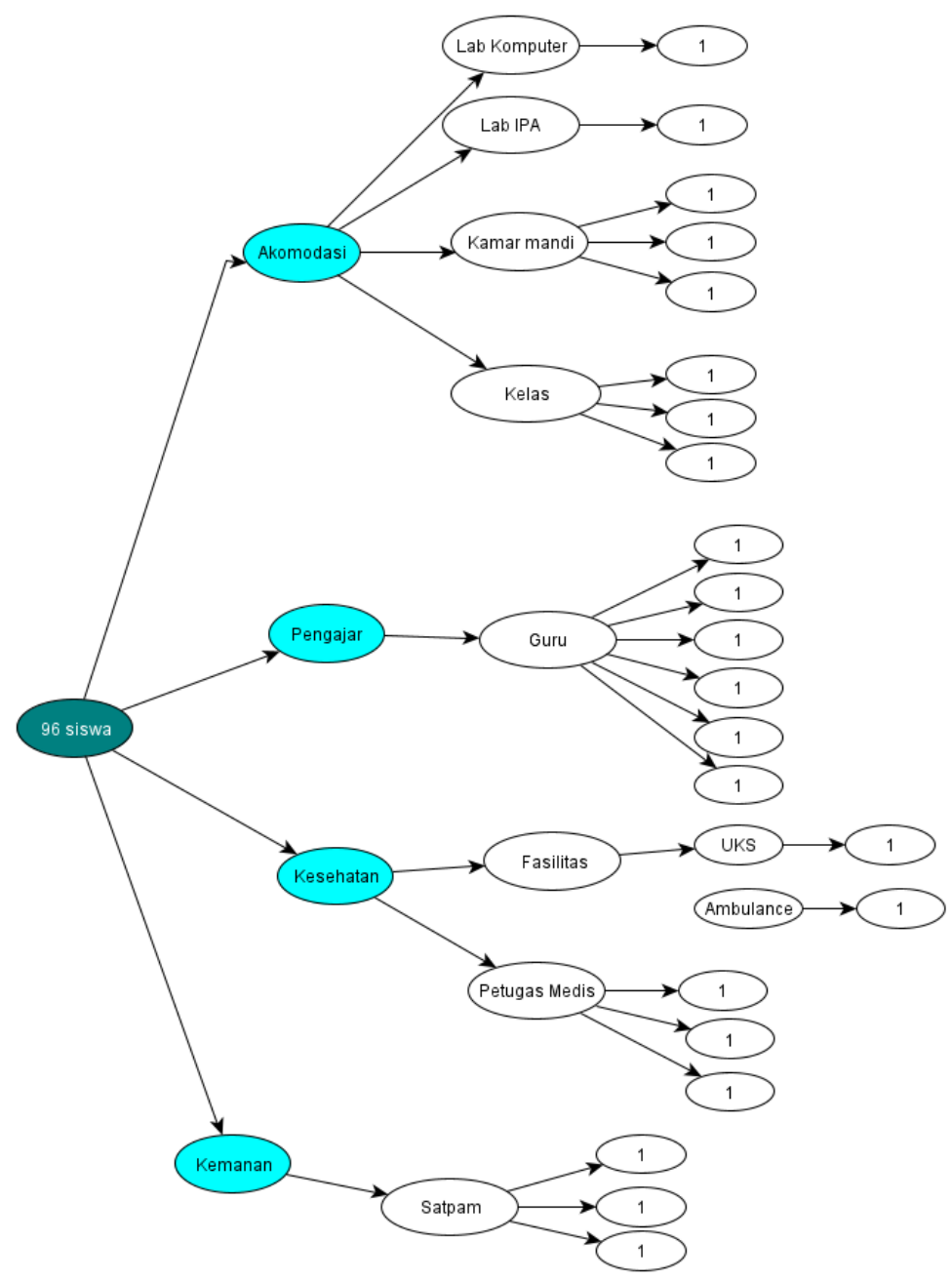

Gambar 4. Pertumbuhan 3

\subsection{Pertumbuhan 4}

Pada pertumbuhan 4, jumlah siswa menjadi 128 siswa. Dengan bertambahnya jumlah siswa bertambah pula jumlah kelas untuk menampung siswa sebanyak 4 kelas. Kenaikan pertumbuhan 4 hanya pada jumlah siswa dan kelas. 
Jurnal Riset Sistem Informasi Dan Teknik Informatika (JURASIK) Volume 5 Nomor 1 Februari, pp 109-117 ISSN: 2527-5771/EISSN: 2549-7839

http://tunasbangsa.ac.id/ejurnal/index.php/jurasik

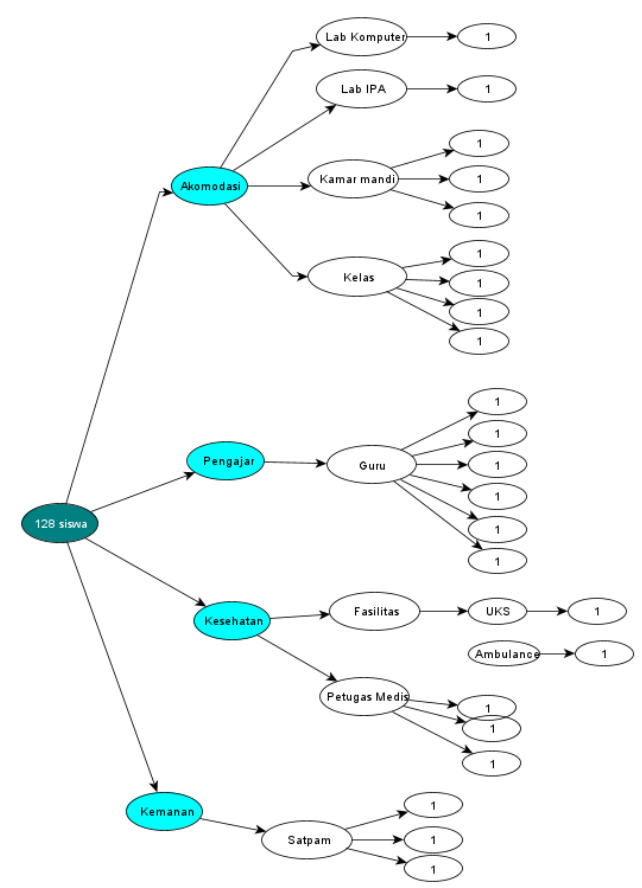

Gambar 5. Pertumbuhan 4

\subsection{Pertumbuhan 5}

Pada pertumbuhan 5, jumlah siswa bertambah menjadi 160 siswa. Kelas juga otomatis bertambah menjadi 5 kelas. Guru juga ditambahkan menjadi 9 orang agar seimbang dengan jumlah siswa.

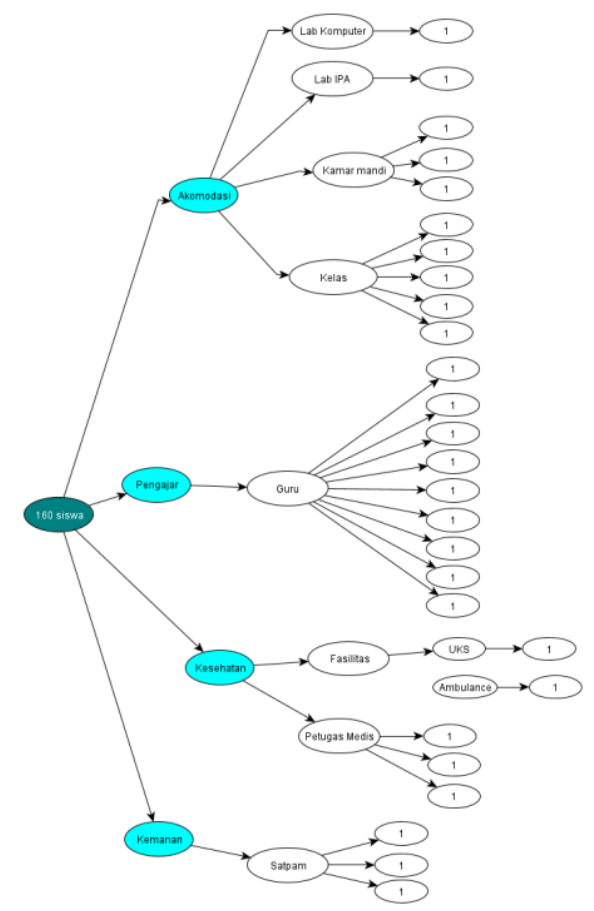

Gambar 6. Pertumbuhan 5 


\subsection{Pertumbuhan 6}

Pada pertumbuhan 6, jumlah siswa menjadi 192 siswa. Jumlah kelas juga bertambah menjadi 6 buah. Karena jumlah siswa yang semakin banyak, kamar mandi juga ditambahkan menjadi 4 buah supaya siswa tidak kekurangan kamar mandi.

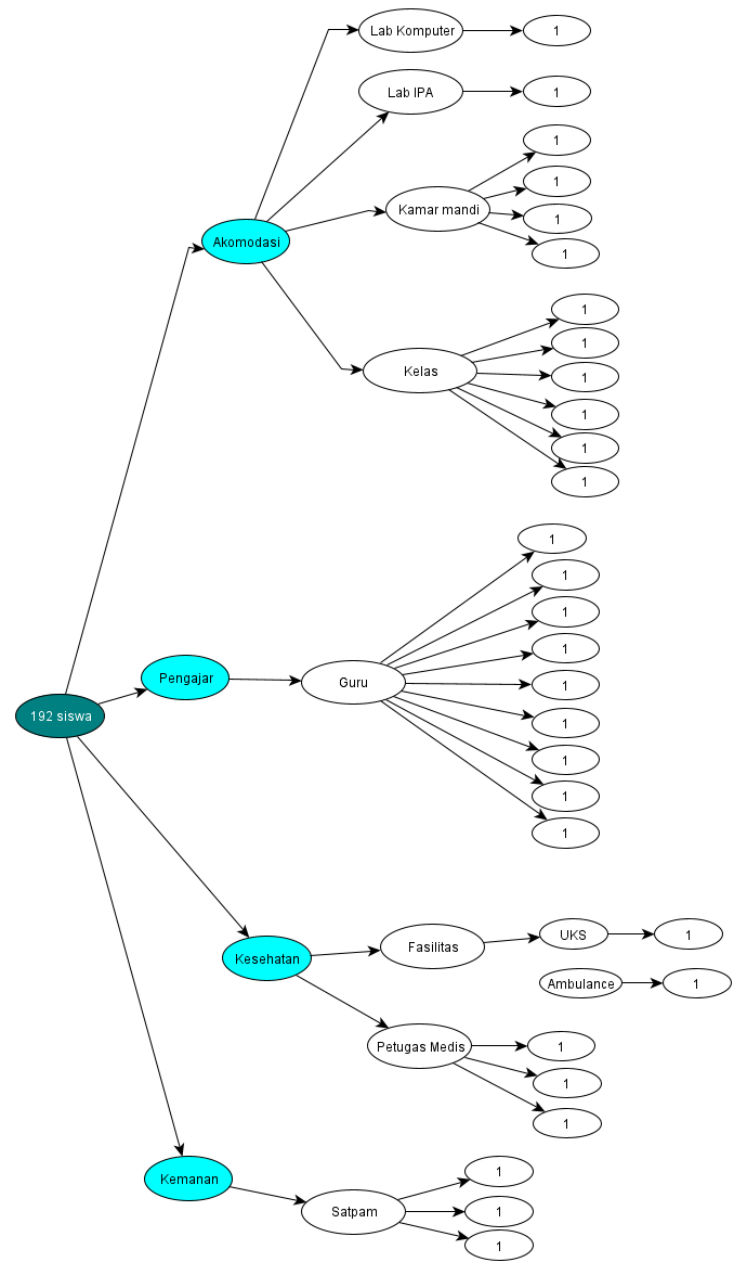

Gambar 7. Pertumbuhan 6

\subsection{Pertumbuhan 7}

Pada pertumbuhan 7, jumlah siswa naik lagi menjadi 224 siswa. Kelas ditambah 1 kelas lagi sehingga totalnya 7 buah. Guru ditambahkan 2 orang sehingga menjadi 11 orang. Sementara fasilitas lainnya tidak bertambah. 


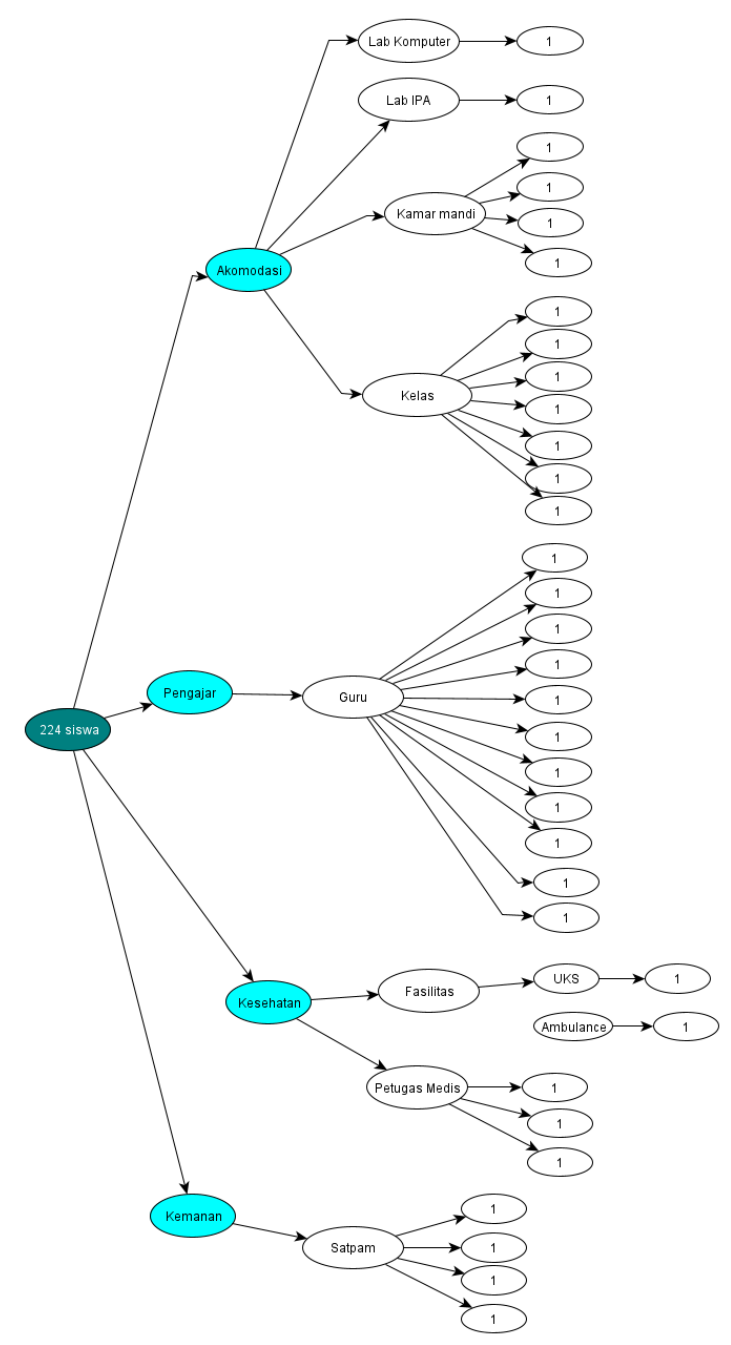

Gambar 8. Pertumbuhan 7

Metrik-metrik yang digunakan untuk mengukur skala dan kompleksitas struktur organisasi didapatkan melalui tree pertumbuhan diatas. Metrik- metrik tersebut adalah jumlah node, jumlah edge, kedalaman rata-rata (average depth), dan weight. Dengan metode AHP didapatkan formula skala dan kompleksitas struktur organisasi (国目目国国).

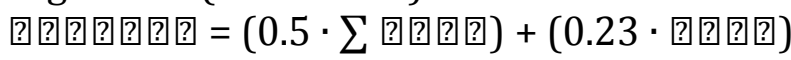

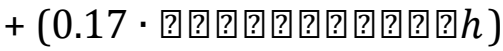

$+(0.055 \cdot$ 固国目 $h$ 国 $)$

Dengan menggunakan formula tersebut, didapatkan

Tabel 1. Pertumbuhan

\begin{tabular}{|c|c|c|c|c|c|c|}
\hline Pertumbuhan & Siswa & Node & Edge & Average Depth & Weight & Ocscale \\
\hline Pertumbuhan 1 & 32 & 14 & 13 & 1,928571429 & 13 & 11,03285714 \\
\hline Pertumbuhan 2 & 64 & 26 & 25 & 1,961538462 & 25 & 20,45846154 \\
\hline Pertumbuhan 3 & 96 & 37 & 36 & 1,972972973 & 36 & 29,09540541 \\
\hline
\end{tabular}


http://tunasbangsa.ac.id/ejurnal/index.php/jurasik

\begin{tabular}{|c|c|c|c|c|c|c|}
\hline Pertumbuhan & Siswa & Node & Edge & Average Depth & Weight & Ocscale \\
\hline Pertumbuhan 4 & 128 & 38 & 37 & 1,973684211 & 37 & 29,88052632 \\
\hline Pertumbuhan 5 & 160 & 42 & 41 & 1,976190476 & 41 & 33,02095238 \\
\hline Pertumbuhan 6 & 192 & 44 & 43 & 1,977272727 & 43 & 34,59113636 \\
\hline Pertumbuhan 7 & 224 & 48 & 47 & 1,979166667 & 47 & 37,73145833 \\
\hline
\end{tabular}

Dari tabel diatas didapatkan grafik petumbuhan sebagai berikut :

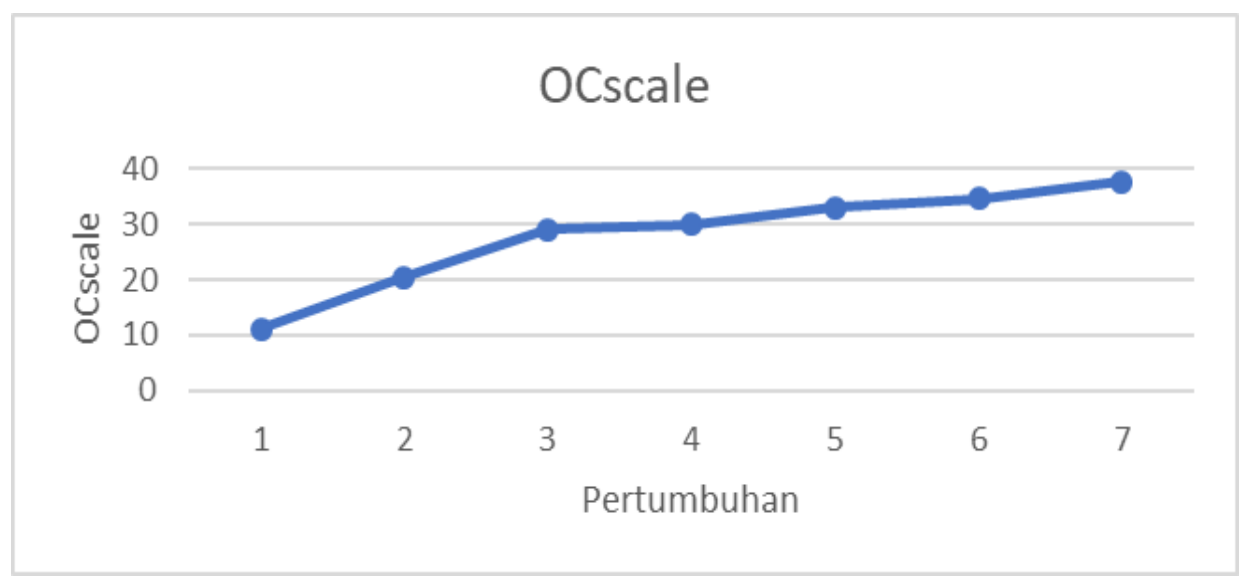

Gambar 9. Grafik pertumbuhan

\section{SIMPULAN}

Hasil yang diperoleh dari pertumbuhan tersebut menyatakan pertumbuhan 7 memiliki nilai pertumbuhan tertinggi sedangkan pertumbuhan 1 memiliki nilai pertumbuhan terendah. Sehingga didapatlah sebuah kesimpulan apabila sebuah sekolah memiliki minimal requirement seperti yang ada pada gambar pertumbuhan 1, maka sekolah belum dapat bekerja secara maksimal dikarenakan hal-hal yang masih belum mumpuni secara sarana dan prasarana. Sedangkan apabila sebuah sekolah memiliki requirement yang lebih banyak, maka sekolah dapat bekerja secara maksimal.

\section{DAFTAR PUSTAKA}

[1] Pendidikan, B. S. Badan Standar Nasional Pendidikan. Jakarta Selatan: BSNP. 2005

[2] Darmanto, E., Latifah, N., \& Susanti, N. Penerapan Metode AHP (Analythic Hierarchy Process) Untuk Menentukan Kualitas Gula Tumbu. Simetris: Jurnal Teknik Mesin, Elektro Dan Ilmu Komputer, 5(1), 75. doi:10.24176/simet.v5i1.139. 2014.

[3] Aziz, A., Anggrainingsih, R., Sihwi, S. W., \& Salamah, U. Penyusunan Arsitektur Visi dan Arsitektur Bisnis Sebagai Tahapan Perancangan Arsitektur Enterprise Universitas Sebelas Maret (UNS) Dengan Framework TOGAF. Conference. 2013.

[4] Irmayanti, H., Wartika, \& Imelda. Pemodelan Arsitektur Enterprise Sekolah Menengah Pertama Negeri 1 Parigi untuk Penerapan Standar Nasional Pendidikan (SNP) Menggunakan Togaf ADM 9.1. Conference. 2017.

[5] Santikarama, I., \& Yulianti, D. T. Pemodelan Enterprise Architecture. Conference. 2017. 